\title{
Comparison of Upper Lip Bite Test with Modified Mallampati Score in Predicting Difficult Intubation
}

\author{
Monish Thomas ${ }^{1}$, Nichelle M. Saldanha ${ }^{2}$ \\ ${ }^{1}$ Resident, ${ }^{2}$ Senior Resident, \\ Department of Anaesthesiology, Father Muller Medical College, Mangaluru -575002 \\ Corresponding Author: Nichelle M. Saldanha
}

DOI: https://doi.org/10.52403/ijshr.20220101

\begin{abstract}
Background and Aims: Identifying a patient with a difficult airway is important in planning anaesthetic management so that endotracheal intubation can be achieved safely. This study aims to compare modified Mallampati score with Upper Lip Bite Test to predict difficult intubation using intubation difficulty scale.

Materials and methods: A prospective study was carried on 104 patients, both sexes aged between 18 to 60 years scheduled for elective surgeries under general anaesthesia fulfilling inclusion and exclusion criteria. Patient airway was evaluated by MMT and ULBT preoperatively. Predictors of difficult endotracheal intubation were assigned to MMT class III and IV, ULBT class III. After premedication and induction laryngoscopy was performed. After successful intubation Intubation difficulty score was noted down based on the sum of seven assessing parameters. A score $>5$ was considered difficult intubation.

Results: The incidence of difficult intubation in the study was $10.6 \%$ (i.e. 11 out of 104 patients). In this study ULBT had a higher sensitivity $(90.9 \% \quad \mathrm{v} / \mathrm{s} \quad 18.20 \%)$, specificity (95.7\% v/s 75.3\%) PPV (71.4\% v/s 8\%) and NPV (98.9\% v/s 88.6\%) than that of MMT

Conclusion: Upper lip bite test is better at predicting difficult intubation with higher accuracy when compared to Modified Mallampati test. Both the tests are good predictors of easy intubation.
\end{abstract}

Key words: Upper Lip Bite Test (ULBT), Modified Mallampati test (MMT), Intubation Difficulty scale (IDS), airway assessment. Difficult intubation prediction, Difficult airway

\section{INTRODUCTION}

The incidence of difficult laryngoscopic tracheal intubation is between $1.3 \%$ to $13 \%$ in an operating room setup. ${ }^{(1)}$ Failed intubation or an unanticipated difficult airway, which may lead to interruption of gas exchange even for a few minutes may lead to catastrophic outcomes causing cerebral hypoxia, brain damage and death. ${ }^{(2,3)} 30-40 \%$ of the anaesthesia related deaths are attributed to the inability to manage the difficult airway. ${ }^{(3)}$

Many tests have been proposed to clinically identify patients preoperatively who may have difficult laryngoscopy. Tests that are commonly used for airway evaluation are thyromental distance, prediction scores devised by Wilson, Sternomental distance, Inter incisor distance, Lower jaw length, subluxation of the mandible, chin protrusion and atlantooccipital extension. However, no test or method has been devised to predict difficult intubation with $100 \%$ accuracy.

The Mallampati test was initially proposed by Mallampati S R and was later modified by Samsoon and Young into four classes. The test was classified based on visualisation of pharyngeal structures with the mouth fully open with the tongue maximally protruding out and without phonation. The observer is to assess the size of the tongue with other structures in the oropharynx and the ability to open the mouth. However, some meta-analysis reports indicated that this classification has 
relatively high specificity but low sensitivity and a high number of false-positive results. ${ }^{(2)}$

The upper lip bite test (ULBT) was developed by Khan et al in 2003. The test is classified according to the ability to bite the upper lip with the lower teeth thus assessing the range and freedom of movement of the mandible and the architecture of the teeth. However, ULBT is not popular due to a lack of familiarity and a definite recommendation for its usage. (2)

Intubation Difficulty score was devised by Adnet et al. It is a numerical score derived by adding seven parameters known to be associated with difficult intubation. The seven parameters are the number of supplementary operators, number and type of alternative techniques used, laryngoscopic grades, subjective lifting force, the use of external laryngeal manipulation and mobility or position of the vocal cords. The total score is the sum of divergence from a zero difficult "ideal" intubation. $^{(4)}$

In the present study, the upper lip bite test is compared with modified Mallampati classification in predicting difficult laryngoscopic intubation It has been hypothesised that the upper lip bite test can be an alternative to the Modified Mallampati test as an effective bedside tool to assess intubation difficulty.

\section{Aim \& Objectives of the Study}

To compare modified Mallampati score with Upper Lip Bite Test to predict difficult intubation using intubation difficulty scale.

\section{MATERIALS \& METHODS}

Ethics committee approval was taken before starting the study and written informed consent were obtained from the patients involved in the study.

104 American Society of Anesthesiologists (ASA) physical status Class I and II patients aged between 18 to 60 years undergoing elective surgery under general anaesthesia with tracheal intubation were enrolled for this prospective, Hospitalbased, Observational descriptive validation study.

\section{Inclusion Criteria (Cases)}

1. Patients scheduled for elective surgery requiring intubation under general anaesthesia.

2. Age between 18 and 60 years of either sex.

3. ASA physical status Class I and II.

\section{Exclusion Criteria}

1. Patient refusal to take part in the study

2. Patients with-Edentulous, Neck contracture, cervical spine pathology.

3. Emergency cases.

4. Pregnant patients.

5. Malformed or deformed airways like Marfan and Pierre-Robin Syndromes.

6. Mentally incapacitate patients.

Preoperatively a complete medical history along with a thorough evaluation of all the systems, particularly the airways was done. The assessment methods were explained in detail to the patients and also explain the purpose of the research study and obtained their consent. The demographic details (age, sex, weight, height, BMI) and airway pathology or active infection, dentition status as well as snoring was recorded. The procedure of general anaesthesia and the surgery was explained to the patient in their language following which baseline vitals was recorded.

Then patients were made to sit with head in the neutral position, the mouth fully opened and tongue maximally protruded without phonation, while the observer looks into pharyngeal structures, the view was graded as follows using Modified Mallampati Classification:

Class $\mathrm{I}=$ soft palate, fauces, uvula and pillars seen

Class II = soft palate, fauces, and portion of uvula seen

Class III $=$ soft palate and base of uvula seen

Class IV = soft palate not visible 


\section{The modified Mallampati classification for difficult laryngoscopy and intubation}
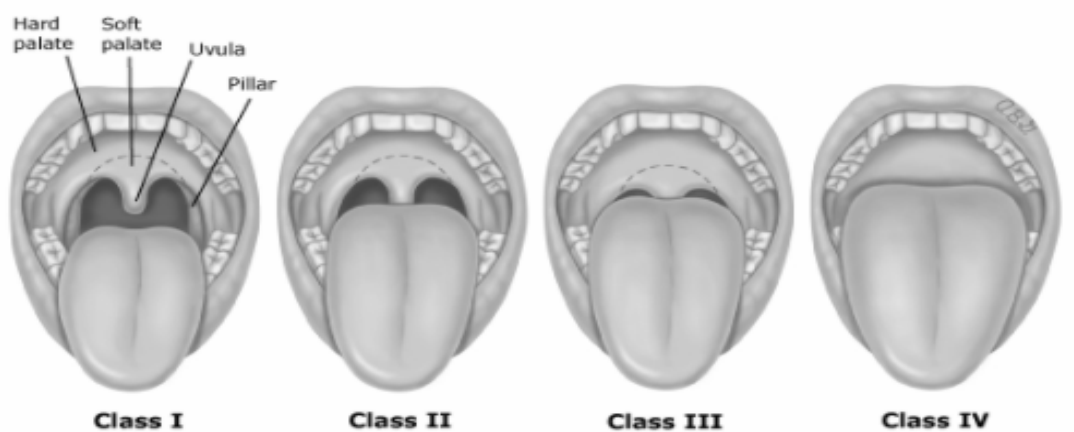

Figure 1: Modified Mallampati Classification ${ }^{(5)}$

The patients were asked to perform the Upper Lip Bite Test which was graded asClass 1 - lower incisors can bite the upper lip above the vermilion line Class 2 - lower incisors can bite the upper lip below the vermilion line Class 3 - the lower incisors cannot bite the upper lip
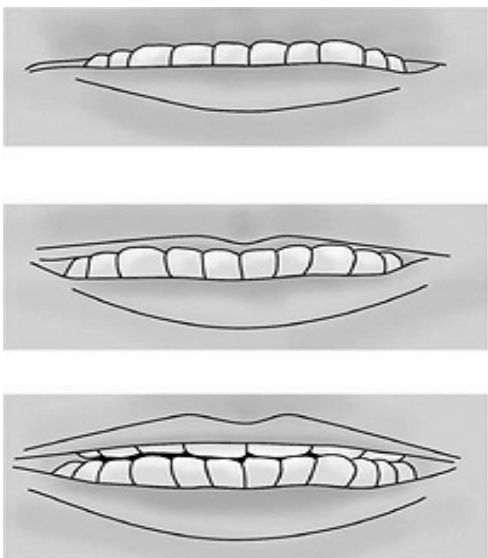

Class I - Lower incisors can bite upper lip above vermilion line

Class II - Lower incisors can bite upper lip below vermilion line

Class III - Lower incisors cannot bite upper lip

Figure 2: Upper lip bite test ${ }^{(6)}$

ULBT class 3 and MMT class III and IV were considered potentially difficult intubation.

All patients were premedicated with Tab. Pantoprazole 40mg HS and Tab. Diazepam 5mg HS and were kept nil per oral, as per ASA guidelines before surgery.

In the Operation theatre, standard monitoring of pulse-oximetry, non-invasive blood pressure, and 5-lead electrocardiography was recorded and an intravenous line with 18G cannula secured, infusion Ringer Lactate/Normal Saline was started. Difficult airway cart was kept ready in the operation theatre.

Patients were positioned to obtain adequate neck extension, pre oxygenated with $100 \%$ oxygen for a minimum of 3 minutes and premedicated with Injection
Glycopyrrolate $0.01 \mathrm{mg} / \mathrm{kg}$ IV and Injection Fentanyl 2mcg/kg IV. Patients were induced with Injection Propofol 2mg/kg IV slowly till there was a loss of response to verbal commands, paralyzed with injection Suxamethonium $2 \mathrm{mg} / \mathrm{kg}$ IV to facilitate tracheal intubation with adequate sized Macintosh blade. The airway was secured with adequate size portex endotracheal tube. All tracheal intubations were performed by an anesthesiologist who was blinded to the preoperative measurements.

Successful intubation was confirmed by bilateral auscultation of the lungs and Capnography, following which the Intubation Difficulty score was noted down. The total IDS score ranges from zero to infinity. 


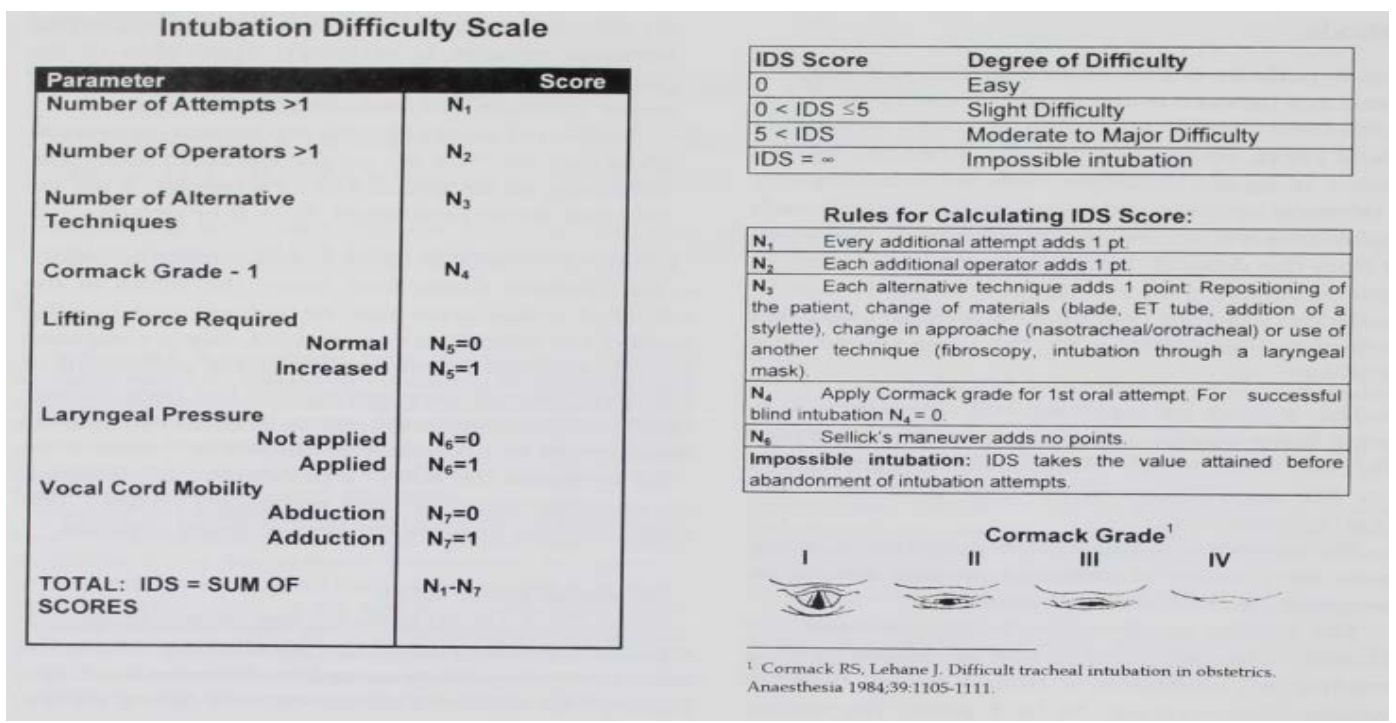

Figure 3: Intubation difficulty scale ${ }^{(7)}$

General anaesthesia was maintained with oxygen, nitrous oxide, Isoflurane, FiO2 of 0.4 and muscle relaxation with Vecuronium $0.02 \mathrm{mg} / \mathrm{kg}$ IV as needed. Ventilation was maintained to keep the endtidal CO2 between 35-40 mmHg.

At the end of the procedure, patients received Inj. Ondansetron $0.01 \mathrm{mg} / \mathrm{kg}$ maximum of $4 \mathrm{mg}$ IV as anti-emetic and Inj.Paracetamol $1 \mathrm{gm}$ IV as an antiinflammatory agent. Patients were adequately reversed from muscle relaxant with Inj. Neostigmine $0.05 \mathrm{mg} / \mathrm{kg}$ and Inj. Glycopyrrolate $0.01 \mathrm{mg} / \mathrm{kg}$ at the end of surgery and was extubated before being shifted to the post-operative ward.

\section{Statistical analysis}

Data will be entered in Microsoft Excel 2007 and analyzed using SPSS version 22.0.

Mean \pm SD, frequency and percentage for data following normal distribution. Data will be presented as tables and figures as appropriate. Sensitivity, Specificity, Positive Predictive value, and Negative Predictive value will be analysed. Categorical data will be analyzed by Chi square test.

\section{RESULTS}

Males constituted $51 \%$ of the study while females formed $49 \%$ of the study population. The demographic details of the study population are listed in table 1 .
Table 1 : Demographic details

\begin{tabular}{|c|c|c|c|c|c|}
\hline \multicolumn{6}{|c|}{ Statistics } \\
\hline & & Age & height & weight & BMI \\
\hline $\mathbf{N}$ & Valid & 104 & 104 & 104 & 104 \\
\hline \multicolumn{2}{|l|}{ Mean } & 36.68 & 160.99 & 63.85 & 24.622551 \\
\hline \multicolumn{2}{|l|}{ Median } & 35.00 & 160.50 & 65.00 & 24.218750 \\
\hline \multicolumn{2}{|c|}{ Std. Deviation } & 11.992 & 6.519 & 10.170 & 3.8379320 \\
\hline \multicolumn{2}{|c|}{ Minimum } & 18 & 150 & 44 & 18.4911 \\
\hline \multicolumn{2}{|l|}{ Maximum } & 60 & 176 & 94 & 38.6259 \\
\hline \multirow[t]{3}{*}{ Percentiles } & 25 & 27.00 & 156.00 & 58.00 & 22.444559 \\
\hline & 50 & 35.00 & 160.50 & 65.00 & 24.218750 \\
\hline & 75 & 47.00 & 166.00 & 69.00 & 25.676401 \\
\hline
\end{tabular}

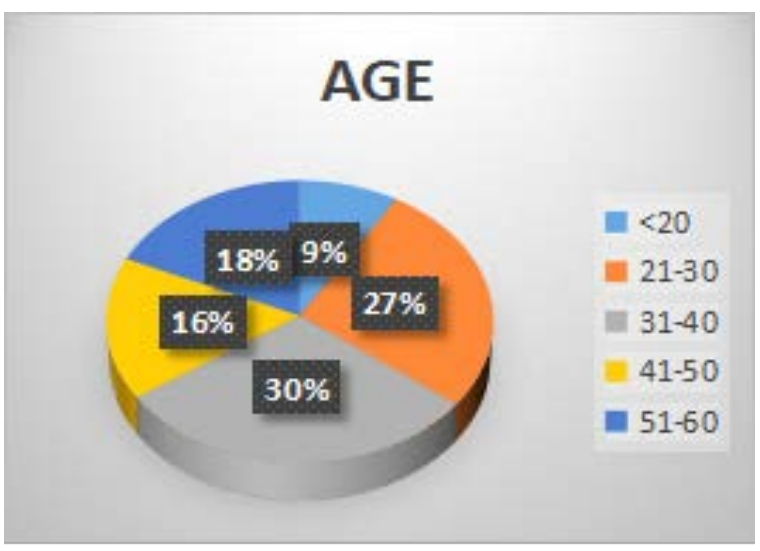

Figure 4: Age distribution

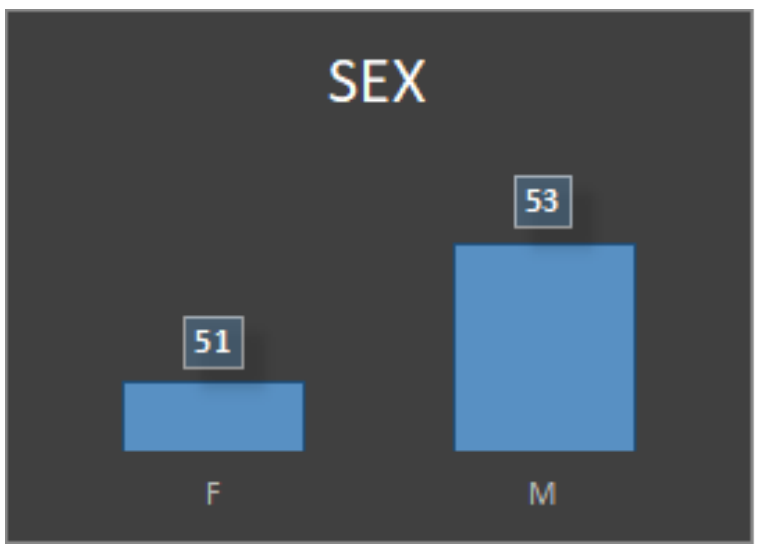

Figure 5: Sex distribution 
Monish Thomas et.al. Comparison of upper lip bite test with modified Mallampati score in predicting difficult intubation

Table2. Distribution of study population according to Modified Mallampati test (MMT)

\begin{tabular}{|c|c|c|}
\hline & $\begin{array}{c}\text { Modified Mallampati } \\
\text { Test(MMT) }\end{array}$ & Valid Percent \\
\hline Grade I & 21 & 20.2 \\
\hline Grade II & 58 & 55.8 \\
\hline Grade III & 25 & 24 \\
\hline Grade IV & 0 & 0 \\
\hline Total & $\mathbf{1 0 4}$ & $\mathbf{1 0 0}$ \\
\hline
\end{tabular}

79 Patient with MMT classification I and II were categorised as easy intubation (76\%) while 25 patients belonged to MMT grade III and IV belonged to difficult intubation category (24\%). However, there were no patients in Mallampati IV group.

Table 3: Distribution of study population according to Upper Lip Bite test (ULBT)

\begin{tabular}{|c|c|c|}
\hline & Upper lip bite test (ULBT) & Valid Percent \\
\hline Grade I & 52 & 50 \\
\hline Grade II & 38 & 36.5 \\
\hline Grade III & 14 & 13.5 \\
\hline Total & $\mathbf{1 0 4}$ & $\mathbf{1 0 0}$ \\
\hline
\end{tabular}

90 Patients were predicted to be easy intubation (86.5\%) according to ULBT. 52 patients in grade I and 38 patients in grade II. 14 patients (ULBT grade III) were predicted to be difficult intubation (13.5\%).

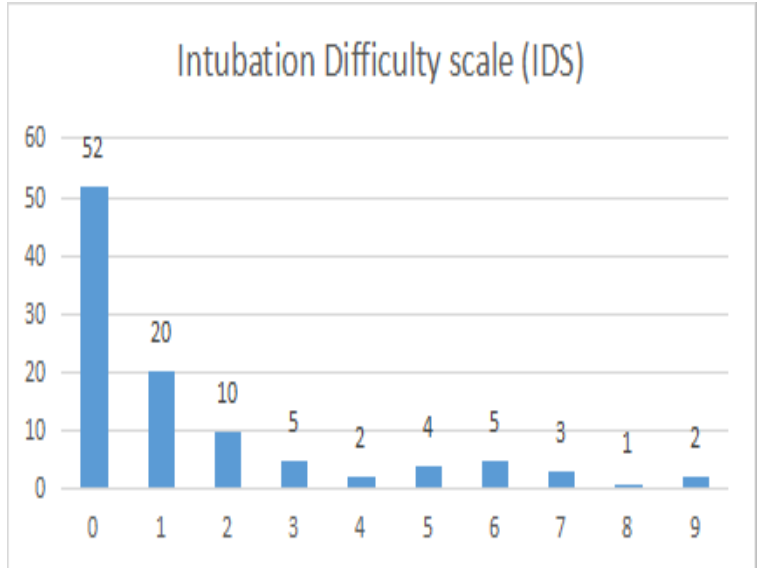

Figure 6: Distribution of Intubation difficulty scale scores

\begin{tabular}{|c|c|c|}
\hline & $\begin{array}{l}\text { Intubation Difficulty } \\
\text { scale (IDS) }\end{array}$ & Valid Percent \\
\hline Easy & 93 & 89.4 \\
\hline Difficult & 11 & 10.6 \\
\hline Total & 104 & 100 \\
\hline
\end{tabular}

Out of the 104 patients 11 patients were difficult intubation (i.e. IDS score $>5$ ) while the rest 93 patient were classified as easy intubation (I.e. IDS score $\leq 5$ ). There were no impossible intubations cases in the study population. Figure 5 shows the distribution of IDS score.
Table 5: Modified Mallamapati Test v/s Intubation difficulty scale

\begin{tabular}{|l|c|c|c|c|}
\hline & \multicolumn{4}{|c|}{ Intubation difficulty scale } \\
\hline \multirow{3}{*}{$\begin{array}{l}\text { Modified Mallamapati } \\
\text { Test }\end{array}$} & & Easy & Difficult & total \\
\cline { 2 - 5 } & Easy & 70 & 9 & 79 \\
\cline { 2 - 5 } & Difficult & 23 & 2 & 25 \\
\cline { 2 - 5 } & Total & $\mathbf{9 3}$ & $\mathbf{1 1}$ & $\mathbf{1 0 4}$ \\
\hline
\end{tabular}

Table 6: Upper lip Bite test v/s Intubation difficulty scale

\begin{tabular}{|c|c|c|c|c|}
\hline & \multicolumn{4}{|c|}{ Intubation difficulty scale } \\
\hline \multirow{3}{*}{ Upper lip Bite test } & & Easy & Difficult & total \\
\cline { 2 - 5 } & Easy & 89 & 1 & 90 \\
\cline { 2 - 5 } & Difficult & 4 & 10 & 14 \\
\cline { 2 - 5 } & Total & $\mathbf{9 3}$ & $\mathbf{1 1}$ & $\mathbf{1 0 4}$ \\
\hline
\end{tabular}

Table 7: Validity of MMT and ULBT

\begin{tabular}{|l|c|c|}
\hline \multicolumn{1}{|c|}{ Parameters } & MMT & ULBT \\
\hline True Negative & 70 & 89 \\
\hline True Positive & 2 & 10 \\
\hline False Negative & 9 & 1 \\
\hline False Positive & 23 & 4 \\
\hline Sensitivity & $18.20 \%$ & $90.90 \%$ \\
\hline Specificity & $75.30 \%$ & $95.70 \%$ \\
\hline Positive Predictive Value & $8.00 \%$ & $71.40 \%$ \\
\hline Negative Predictive Value & $88.60 \%$ & $98.90 \%$ \\
\hline Diagnostic Accuracy & $69.23 \%$ & $95.19 \%$ \\
\hline P Value & 0.7310 & $\underline{\mathbf{0 . 0 0 1}}$ \\
\hline
\end{tabular}

\section{DISCUSSION}

Identifying a patient with a difficult airway is important in planning anaesthetic management so that endotracheal intubation can be achieved safely. This has led to the need for simple and reliable tests to predict difficult intubation. ${ }^{(1)}$ In this study, we have compared Modified Mallampati Test (MMT) and Upper lip Bite Test (ULBT). These are simple and easily demonstratable bedside tests, non-invasive and inexpensive.

In this study of 104 patients undergoing elective surgery under general anaesthesia, MMT and ULBT were used as screening tests for predicting difficult intubation which was evaluated with the Intubation difficulty scale (IDS).

In this study the incidence of difficult intubation was $10.6 \%$ that is 11 out of 104 patients were difficult intubation (i.e. IDS score $>5$ ) 104 patients. 10 out of 14 ULBT class III patients belonged to IDS difficult intubation criteria, while in MMT class III and IV, only 2 out of 25 belonged to IDS difficult intubation criteria. The incidence of difficult intubation in the Khan et al ${ }^{(8)}$ study was $5.7 \%$ and that in Eberhart et al ${ }^{(9)}$ was $12 \%$. There was no incidence of failed intubation in our study. 
The sensitivity of ULBT in our study was $90.90 \%$. The high sensitivity of the test would mean that the test would identify patients with difficult intubation. Asghar Ali et $\mathrm{al}^{(10)}$ and Naithani et $\mathrm{al}^{(11)}$ had a sensitivity of $87.5 \%$ and $92.8 \%$ respectively for ULBT. Khan et $\mathrm{al}^{(8)}$ had reported a sensitivity of 76.5\% for ULBT. Mohan et al ${ }^{(12)}$ had reported a sensitivity of only $40 \%$.

The sensitivity of MMT in our study was $18.20 \%$. Lower sensitivities for MMT were reported in studies conducted by Asghar et al ${ }^{(10)}(19.6 \%)$ and Lundstrom et al(13) reported 22\%. But higher sensitivity has been reported by Khan et al ${ }^{(8)}(82 \%)$ and Eberhart et al ${ }^{(9)}(70 \%)$. This discrepancy is may be due to inaccurate classification, inconsistent technique and patient factors such as inability to perform what was asked despite demonstration. ${ }^{(14)}$

A high specificity suggests that the tests would predict easy intubations correctly. The specificity of MMT in this study was $75.30 \%$. The specificity of MMT in studies by Khan et $\mathrm{al}^{(8)}$, Eberhart et $\mathrm{al}^{(9)}$, Oates et $\mathrm{al}^{(15)}$ were $66.8 \%, 61 \%, 82 \%$ respectively. A wide range of specificity for MMT may be attributed to factors such as poor demarcation between various classes and involuntary phonation. ${ }^{(1)}$

The specificity of ULBT in this study was $95.70 \%$. The specificity value of ULBT is similar to that of the study by Karci et $\mathrm{al}^{(16)}(97.6 \%)$ and Eberhart et $\mathrm{al}^{(9)}$ $(92.5 \%)$. Khan et $\mathrm{al}^{(8)}$ had a specificity of $88.7 \%$ for ULBT in their trial.

Positive predictive value (PPV) suggests the percentage of correctly predicted difficult intubation as a proportion of all predicted difficult intubations. The positive predictive value of MMT in the current study was $8.00 \%$.this is lower when compared to the PPV noted in the studies of Khan et $\mathrm{al}^{(8)} \quad(13 \%)$, Honarmand et $\mathrm{al}^{(17)}$ (18.3\%) and Eberhart et $\mathrm{al}^{(9)}$ (19.5\%). This can be attributed to the fact that airway assessment was done by the same examiner thus avoiding inter-observer variability.

The positive predictive value of ULBT was $71.40 \%$ in this study Khan et $\mathrm{al}^{(8)}$ and Eberhart et $\mathrm{al}^{(9)}$ showed PPV of only $28.9 \%$ and $33.6 \%$ respectively in their studies. Honarmand et $\mathrm{al}^{(17)}$ had a PPV of 93\% in their study.

Negative Predictive Value (NPV) suggests the percentage of correctly predicted difficult intubation. NPV of MMT and ULBT in this study was $88.60 \%$ and $98.90 \%$ respectively. Khan et $\mathrm{al}^{(8)}$ showed an NPV of $98 \%$ for both MMT and ULBT. Hester et $\mathrm{al}^{(18)}$ the NPV of MMT and ULBT were $79 \%$ and $90 \%$ respectively. This shows that these tests can be good predictors of easy intubations rather than positive predictors of difficult intubation which has a very low incidence as concluded by Eberhart et $\mathrm{al}^{(9)}$.

The diagnostic accuracy of ULBT was higher at $95.19 \%$ than that of MMT, which was only $69.23 \%$. Khan et $\mathrm{al}^{(8)}$ in their study had a diagnostic accuracy of 88\% for ULBT and $67.7 \%$ for MMT. The diagnostic accuracies were seen in other studies like Hester et $\mathrm{al}^{(18)}$ at $90 \%$, and Eberhart et al $^{(9)}$ at $84.9 \%$ for ULBT while it was only $64 \%$ and $62.1 \%$ for MMT.

Thus, in this study ULBT had a higher sensitivity $(90.9 \%$ v/s $18.20 \%)$, specificity (95.7\% v/s 75.3\%) PPV (71.4\% v/s 8\%) and NPV (98.9\% v/s 88.6\%) than that of MMT. An ideal test should be highly sensitive than specific with a high PPV, to predict difficult intubations correctly and avoid false positives. Also, the diagnostic accuracy of ULBT $95.9 \%$ is greater than MMT (69.23\%) Both tests had high NPV suggesting these tests are good predictors of easy intubation. The presence of ULBT class III is considered the best predictor of difficult intubation and the absence of MMT class IV helps in ruling out difficult intubation.

\section{CONCLUSION}

The upper lip bite test is a better test with higher accuracy at predicting difficult intubation when compared with the Modified Mallampati test, but cannot be used as a single predictor of difficult 
intubation. Both the tests are good predictors of easy intubation.

\section{Limitations of the study}

This study was only conducted in patients undergoing elective surgery. Emergency patients who are considered to be difficult intubated were not involved in this study. Hence this study cannot be generalised to all the subgroups of the general population. Also, the sample size is small has an allowable error of $2 \%$.

Some patients were unable to elicit/ understand ULBT despite repeated demonstrations or due to the absence of teeth or ability to move the mouth. Only participants meeting those criteria were included in this study.

\section{Acknowledgement: None}

\section{Conflict of Interest: None}

\section{Source of Funding: None}

\section{Ethical Approval: Approved}

\section{REFERENCES}

1. Balakrishnan R, Mathew P \& Thomas R. (2018) Comparison of Modified Mallampati Test and Upper Lip Bite Test in Prediction of Difficult Endotracheal Intubation: A Prospective Study. Int J Anaesth Res, 1(1): 1-5. DOI: http://dx.doi.org/10.21088/ijaa. 2349.8471.5818.19

2. $M$ OK, M NP, M TU, W J, S B. A Comparison of Upper Lip Bite Test with Modified Mallampati Classification in Predicting Difficult Laryngoscopic Intubation. Thai J Anesthesiol. 2010;36:1-8.

3. Boolaky DS, Dept of anesthesia, D.Y. Patil Medical College, Mauritius. Comparative study of upper lip bite test \& modified mallampati score in predicting difficult intubation. J med sci clin res [Internet]. 2018;6(4). Available from: http://dx.doi.org/ 10.18535/jmscr/v6i4.74

4. Benumof JL. Intubation difficulty scale: anticipated best use. Anesthesiology [Internet]. 1997; 87(6):1273-4. Available from: http://dx.doi.org/10.1097/00000542199712000-00002

5. Up To Date [Internet]. Uptodate.com. [cited 2021 Dec 12]. Available from: https://www.uptodate.com/contents/image?i mageKey=EM\%2F75229

6. Themes UFO. Difficult and Failed Intubation: Strategies, Prevention and management of airway-related Catastrophes in obstetrical patients [Internet]. Aneskey.com. 2016 [cited 2021 Dec 12]. Available from: https://aneskey.com/ difficult-and-failed-intubation-strategiesprevention-and-management-of-airwayrelated-catastrophes-in-obstetrical-patients/

7. Adnet F, Borron SW, Racine SX, Clemessy JL, Fournier JL, Plaisance P, et al. The intubation difficulty scale (IDS): proposal and evaluation of a new score characterizing the complexity of endotracheal intubation. Anesthesiology [Internet]. 1997; 87(6): 1290-7. Available from: http://dx.doi.org/ 10.1097/00000542-199712000-00005

8. Khan ZH, Kashfi A, Ebrahimkahani E. Acomparison of the upper lip bite test (a simple newtechnique) with modified Mallamapti classification inpredicting difficulty in endotracheal intubation: aprospective blind study. Anesth Analg. 2003;96:595-599.

9. Eberhart LHJ, Arndt C, Cierpka T, Schwanekamp J, Wulf $\mathrm{H}$, Putzke C. The reliability and validity of the upper lip bite test compared with the Mallampati classification to predict difficult laryngoscopy: an external prospective evaluation. Anesth Analg [Internet]. 2005; 101(1):284-9, table of contents. Available from: http://dx.doi.org/10.1213/01.ANE. 0000154535.33429.36

10. Ali MA, Qamar-ul-Hoda M, Samad K. Comparison of upper lip bite test with Mallampati test in the prediction of difficult intubation at a tertiary care hospital of Pakistan. J Pak Med Assoc. 2012;62(10): 1012-5.

11. Naithani U, Gupta G, Keerti K, Gupta M, Meena K, Sharma, et al. Predicting difficult intubation in surgical patients scheduled for general anaesthesia: A prospective study of 435 patients. J evol med dent sci [Internet]. 2013;2(14):2270-86. Available from: http://dx.doi.org/10.14260/jemds/528

12. K DM, L DMR. Comparison of upper lip bite test with thyromental distance for predicting difficulty in endotracheal intubation: A prospective study. Asian Journal of Biomedical and Pharmaceutical Sciences. 2013;3: (22:62-65. 
13. Lundstrøm LH, Vester-Andersen M, Møller AM, Charuluxananan S, L'hermite J, Wetterslev J; Danish Anaesthesia Database. Poor prognostic value of the modified Mallampati score: a meta-analysis involving 177088 patients. $\mathrm{Br} \mathrm{J}$ Anaesth. 2011 Nov;107(5):659-67. doi: 10.1093/bja/aer292. Epub 2011 Sep 26. PMID: 21948956.

14. Vallem B, Thalisetty J, Challapalli SR, Israel $\mathrm{N}$, Gudise $\mathrm{S}$, Murthigari $\mathrm{S}$. Comparison of upper lip bite test with other four predictors for predicting difficulty in intubation. $\mathrm{J}$ evol med dent sci [Internet]. 2015; 4(39):6811-7. Available from: http://dx.doi.org/10.14260/jemds/2015/988

15. Oates JD, Macleod AD, Oates PD, Pearsall FJ, Howie JC, Murray GD. Comparison of two methods for predicting difficult intubation. Br J Anaesth [Internet]. 1991; 66(3):305-9. Available from: http://dx.doi.org/10.1093/bja/66.3.305

16. Karci, A.; Karagöz, S.; Girgin, P.; Bozdoğan, D. G. Comparison of modified Mallampati classification, upper lip bite test and neck circumference in prediction of difficult intubation, European Journal of
Anaesthesiology: June 2011 - Volume 28 Issue - p 236.

17. Honarmand A, Safavi M, Yaraghi A, Attari M, Khazaei M, Zamani M. Comparison of five methods in predicting difficult laryngoscopy: Neck circumference, neck circumference to thyromental distance ratio, the ratio of height to thyromental distance, upper lip bite test and Mallampati test. Adv Biomed Res [Internet]. 2015;4(1):122. Available from: http://dx.doi.org/10.4103/ 2277-9175.158033

18. Hester CE, Dietrich SA, White SW, Secrest JA, Lindgren KR, Smith T. A comparison of preoperative airway assessment techniques: the modified Mallampati and the upper lip bite test. AANA J. 2007;75(3):177-82.

How to cite this article: Monish Thomas, Nichelle M. Saldanha. Comparison of upper lip bite test with modified Mallampati score in predicting difficult intubation. International Journal of Science \& Healthcare Research. 2022; 7(1): 1-8. DOI: https://doi.org/10.52403/ ijshr.20220101 